\title{
ATTENUATION OF MOTORCYCLE HANDLE VIBRATION USING DYNAMIC VIBRATION ABSORBER
}

\author{
Muhammad Iyad Al-Maliki Saifudin, Nabil Mohamad Usamah and \\ Zaidi Mohd Ripin
}

TheVibrationLab, School of Mechanical Engineering, Universiti Sains Malaysia, 14300 Nibong Tebal, SPS, Pulau Pinang, Malaysia

*Email: mezaidi@usm.my, thevibrationlab@gmail.com

Phone: +6045996368; Fax: +6045996912

\begin{abstract}
Motorcycle riders are exposed to hand-transmitted vibration of the hand-arm system due to the vibration of the handle and extended exposure can result in numbness and trembling. One feasible solution to attenuate the handle vibration is by using a dynamic vibration absorber (DVA). In this work a DVA is designed and mounted on the motorcycle handle in order to reduce the vibration at the handle by transferring the vibration from the primary system handle to the secondary mass. Removal of elastomeric material at the DVA mounting locations, symmetry of secondary mass and the direction of DVA attachment influence the vibration absorption. A series of tests conducted show that the vibration on the handle is mainly induced by the engine and there is additional source of vibration from the road surface roughness. Installation of DVA at different locations on the handle resulted in various attenuation levels at different speed in the $\mathrm{x}$ and $\mathrm{z}$ directions. The attenuation level is between 59-68\% in the biodynamic $\mathrm{x}$-directions for speed at 30-50 $\mathrm{kmh}^{-1}$.
\end{abstract}

Keywords: Motorcycle Handle, Vibration Absorber, Hand-Arm Vibration, and Vibration Analysis.

\section{INTRODUCTION}

Motorcycles are one of the major transportation vehicle used in the world because they are cheap with low fuel consumption and easy to handle [1]. The engine vibration and road conditions can result in excessive vibration which will reduce the user comfort [2][3]. The excessive exposure of vibration to the user can cause vascular disorder, muscle disorder, neurological disorder and bone and joint disorder which can be called hand arm vibration (HAVs) [4]. Studies showed that more than $50 \%$ of respondents suffer from discomfort at the hands and the arm and more than $50 \%$ of non-occupational motorcyclist experienced discomfort at their low back, neck, shoulders, elbows, and upper back. Meanwhile occupational motorcyclists experienced greater discomfort [2][5]. 4.2\% of motorcyclist police officer suffered from finger blanching [6]. Standard human vibration exposure limit set by the European Directive (European Directive/2002/44/EC) can be used to achieve the acceptable level to reduce the prevalence of hand arm vibration syndrome. The daily exposure action value (EAV) required users to reduce the any vibration exposure above than $2.5 \mathrm{~ms}^{-2}$ while the exposure limit value (ELV) is 5.0 
$m s^{-2}$. From previous research, the frequency of interest of a motorcycle vibration is in the range of $50 \mathrm{~Hz}$ to $300 \mathrm{~Hz}$ while the vibration magnitude on the motorcycle handlebar is between $2.2 \mathrm{~ms}^{-2}$ to $9.77 \mathrm{~ms}^{-2}$ [2][6][7][8]. The high variance of the exposed vibration magnitude of different respondents are related to several uncontrolled parameters [2]. Some of the uncontrolled parameters are the user handlebar griping force [9][10] and the area of contact between the hand to the vibrating components [11]. Numerous studies have been done to overcome the hand arm vibrations. One technique is with the use of vibration absorber [12][13]. It is a tunable secondary mass with spring and damping properties with natural frequency similar to the excitation force frequency. Examples of application are in electrical grass trimmer [14], a motorcycle handle [7], machine [15] and hand blender [16]. Most studies in the past were mainly done by measuring handle vibration with the motorcycle stationary on the dynamometer [7] or at relatively low speed of up to $10 \mathrm{kmh}^{-1}$ [2] or at a mean velocity of $40 \mathrm{kmh}^{-1}$ [8]. This paper covers the development of dynamic vibration absorber for use on motorcycle handlebar which include on the road test of speed range at $30-50 \mathrm{kmh}^{-1}$.

\section{METHODOLOGY}

\section{Modal analysis of motorcycle handlebar}

Figure 1 shows the measurement nodes located on the motorcycle handlebar labelled with stickers. Modal analysis was carried out with the motorcycle handlebar suspended using rubber chords to represent the free-free condition. A small light weight accelerometer (Dytran 3055B2T) was used to measure the vibration response in the $\mathrm{x}$-axis while an impact hammer (Krisler 9724A5000) was used to excite the motorcycle handlebar. Both are connected to the 8-channel LMS SCADAS mobile. The accelerometer is calibrated and placed on the measured nodes using the roving accelerometer techniques. The signals from the test were recorded to derive the FRF (Frequency Response Function) for each measurement nodes, post processed and displayed on LMS Impact Testing Rev. 8B Software.

a) Motorcycle Handlebar

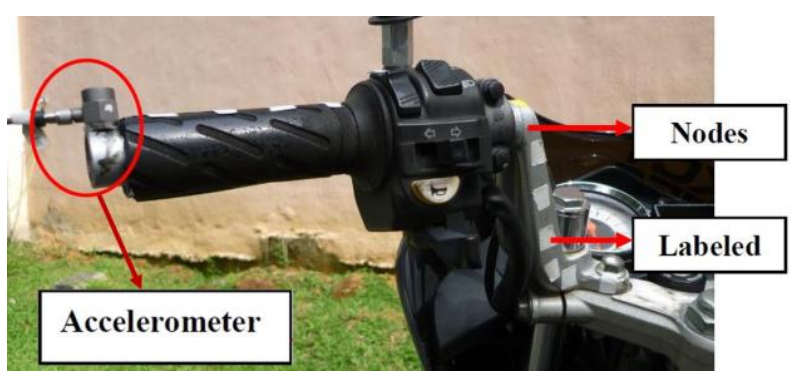

b) Data Acquisition

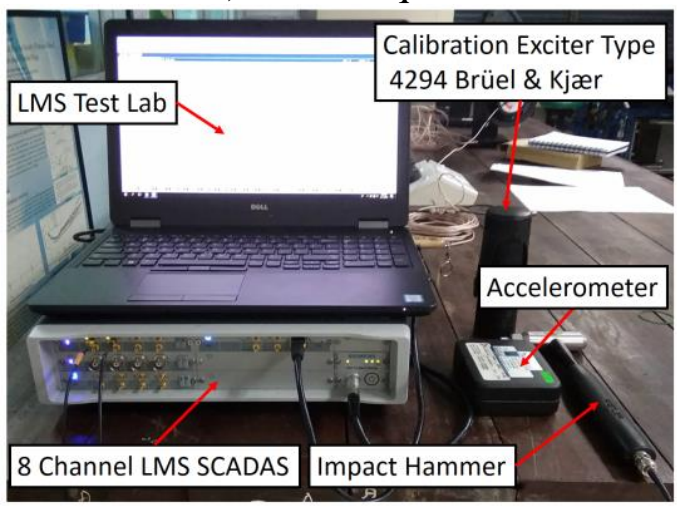

Figure 1. Experimental setup for modal analysis.

a) Motorcycle Handlebar and b) Data Acquisition 


\section{Vibration analysis of Suzuki Belang 150R handlebar on the Road Test}

In order to determine the operating frequency, vibration level and their dominant axis, vibration measurement is carried out on the motorcycle handle. The measurement instruments include one miniature triaxle accelerometer (Dytran, 3023M20), calibrator (B\&K, 4294), FFT analyzer (LMS Scadas Mobile), post-processing software (LMS Test $\mathrm{Lab}$ ), tachometer and a portable computer. The measurement is carried out over a distance of 110 meters straight-flat asphalt road surface. Accelerometers are located on the handlebar, the rider left hand and the motorcycle fork. The accelerometers are connected to the LMS Scadas Mobile running on LMS Test Lab and a portable computer for the data acquisition system. The test is carried out at three different constant speed ranging from $30 \mathrm{kmh}^{-1}$ to $50 \mathrm{kmh}^{-1}$ at $10 \mathrm{kmh}^{-1}$ interval. The vibration level is also measured at the steel parts of the handlebar near the left handgrip. The direction defined is as in the biodynamic axes. The handgrips are held by the rider. Similar experiment is carried out with the attachment of the dynamic vibration absorber to measure and evaluate the effectiveness of the DVA.

a) Handlebar

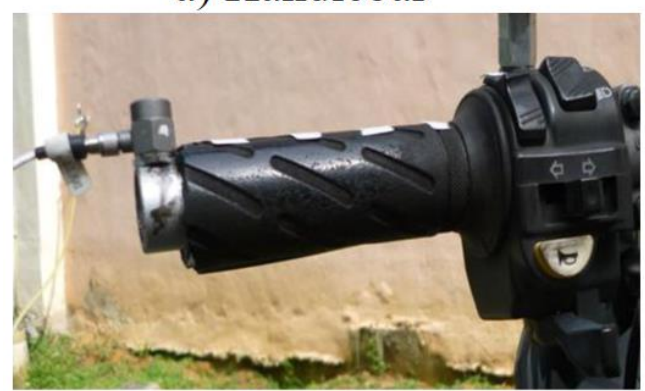

c) Front Fork

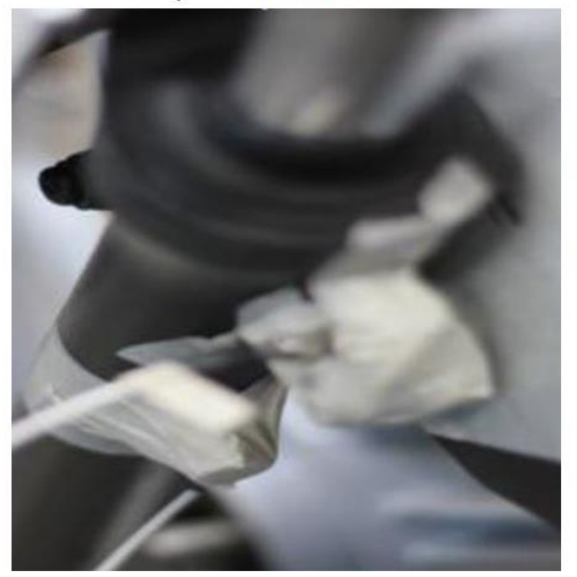

b) Hand

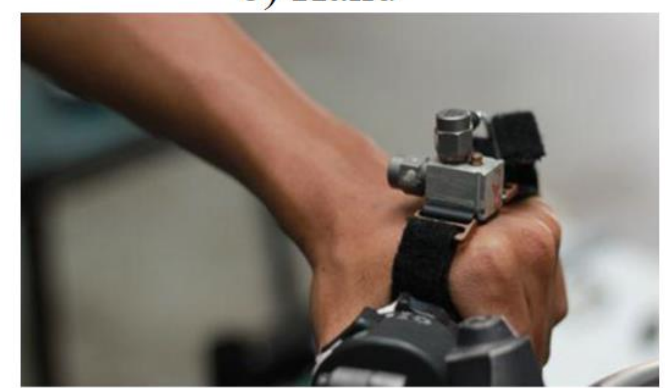

d) LMS SCADAS \& LMS Test Lab

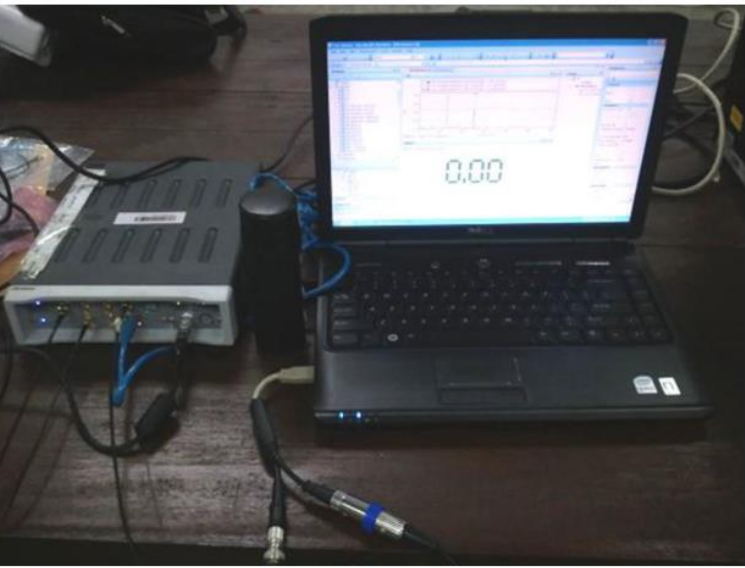

Figure 2. Schematic diagram for the vibration analysis on road test.

a) Handlebar accelerometer b) Hand Accelerometer

c) Front Fork Accelerometer and d) LMS SCADAS \& LMS Test Lab 


\section{RESULTS AND DISCUSSION}

\section{Modal Analysis of Motorcycle Handlebar}

The handlebar dimension of the motorcycles was measured and this is then used in the drawing of the "node" \& "line" functions of the LMS Test Lab to visualize and analyze the vibration for modal analysis. Figure 3 shows the FRF of the handle in $\mathrm{x}$ and $\mathrm{z}$ axes under impact testing. For the $\mathrm{x}$-axis, Mode 2 is the only mode with high participation of $62 \%$ at $131 \mathrm{~Hz}$. While for the z-axis, Mode 1 and Mode 6 with $40 \%$ and $23 \%$ mode participation at $60 \mathrm{~Hz}$ and $297 \mathrm{~Hz}$ respectively. All vibration modes are below $400 \mathrm{~Hz}$ and within the frequency range significant to human arm vibration.

a) $x$-axis

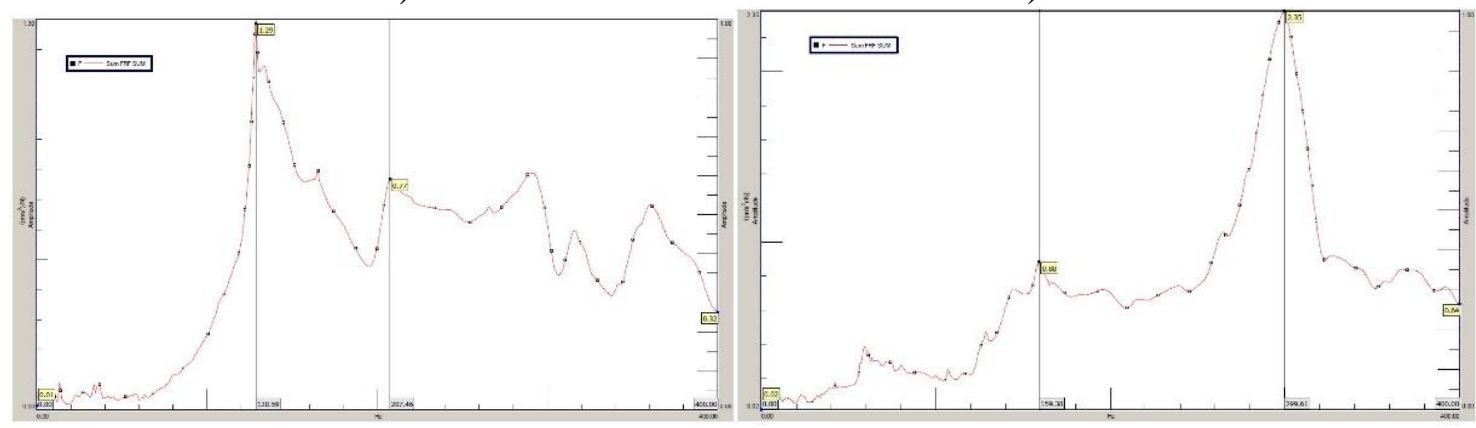

Figure 3. FRF Spectrum of the handlebar (a) x-axis and (b) z-axis

\section{Motorcycle handlebar Response Spectrum on the Road Test}

The RMS acceleration for a series of road tests are listed in Table 1 based on the acceleration of the handlebar at node 1 . The accelerations are highly affected by the speed. The dominant direction is in the $\mathrm{x}$-axis and the $\mathrm{z}$-axis acceleration is always lower and does not follow the trend of the acceleration in $\mathrm{x}$-axis. The response spectra for the RMS accelerations in the $\mathrm{x}$-axis and $\mathrm{z}$-axis are plotted in figure 4. Both axes exhibited frequencies clustering around a fixed frequency at $160 \mathrm{~Hz}$. The relatively constant peak frequency in this case is basically speed independent, which indicated the possibility of resonance within this speed range.

a) $x$-axis

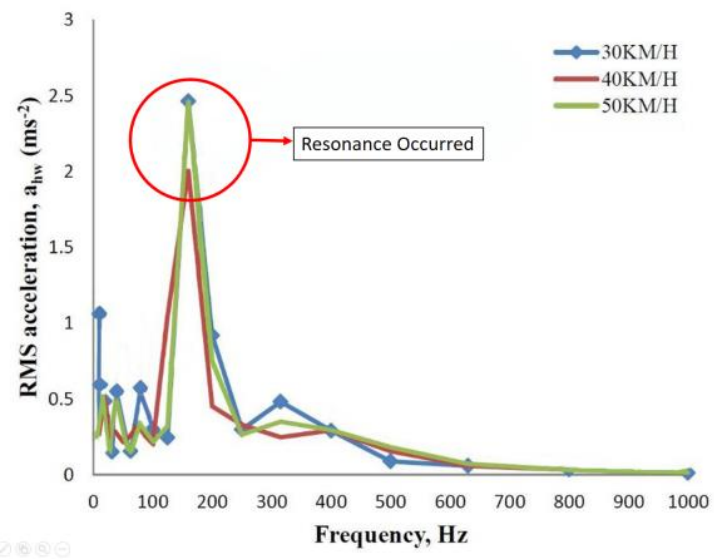

b) z-axis

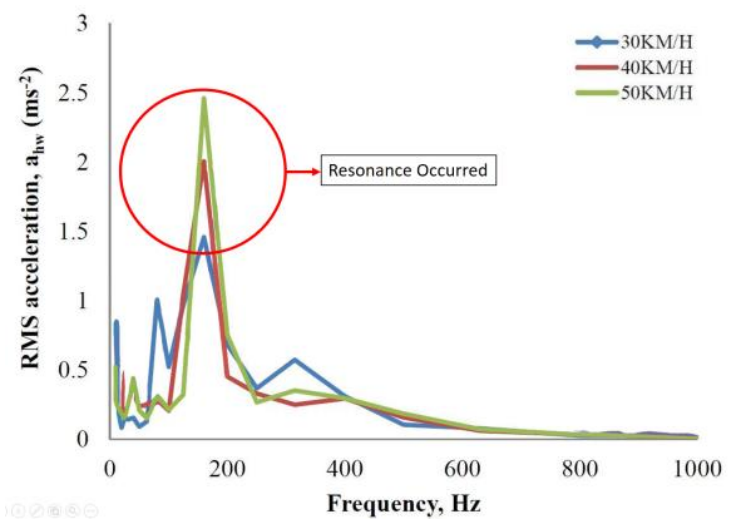

Figure 4. RMS Acceleration Response Spectrum (a) X-axis and (b) z-axis 
Table 1. RMS acceleration for handle

\begin{tabular}{cccc}
\hline $\begin{array}{c}\text { Input Speed } \\
\left(\mathrm{kmh}^{-1}\right)\end{array}$ & \multicolumn{2}{c}{ Acceleration $\left(\mathrm{ms}^{-2}\right)$} & \multirow{2}{*}{$\begin{array}{c}\text { Peak Frequency } \\
(\mathrm{Hz})\end{array}$} \\
\cline { 2 - 3 } & $\mathrm{x}$ & $\mathrm{z}$ & 160 \\
\hline 30 & 2.487 & 1.470 & 160 \\
\hline 40 & 2.218 & 2.023 & 160 \\
\hline 50 & 2.482 & 1.751 &
\end{tabular}

\section{Vibration Attenuation of motorcycle handlebar using added mass}

Figure 5 below shows the comparison of vibration level on the motorcycle handlebar during road test evaluation before and after the installation of the added mass. The higest vibration peak of the x-axis and z-axis at $207.5 \mathrm{~Hz}$ shifted to $200.0 \mathrm{~Hz}$, with the peak vibration attenuation is $59 \%$ and $50 \%$ from $3.32 \mathrm{~ms}^{-2}$ to $1.35 \mathrm{~ms}^{-2}$ and $3.29 \mathrm{~ms}^{-2}$ to $1.65 \mathrm{~ms}^{-2}$ respectively.

a) $\mathrm{x}$-axis

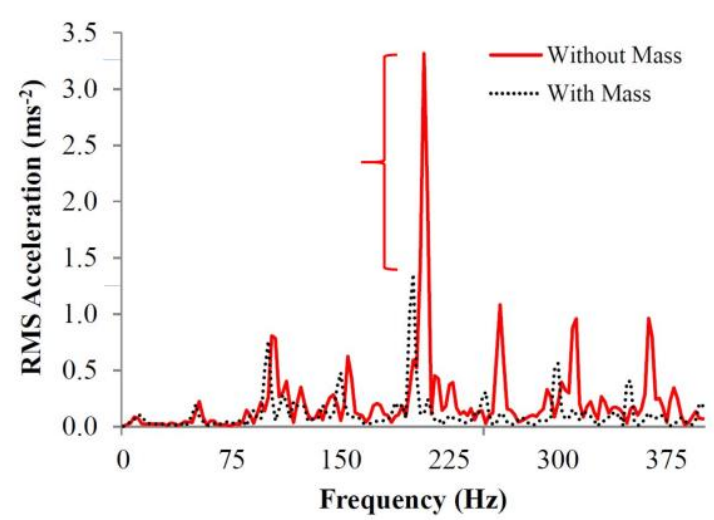

b) z-axis

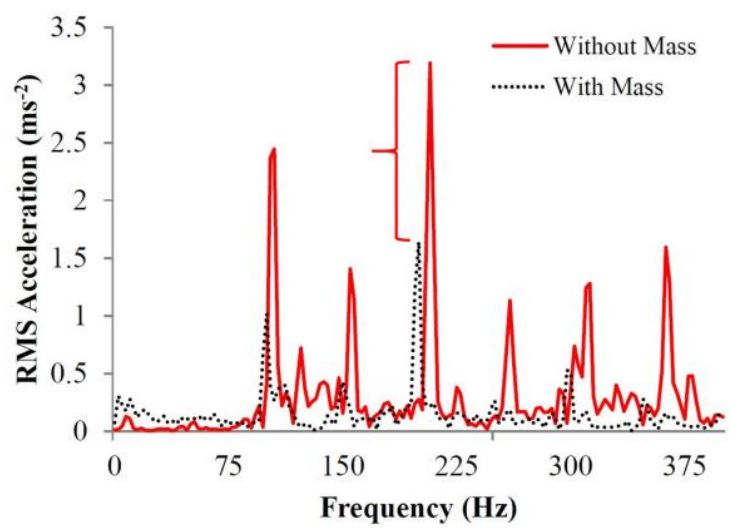

Figure 5. The effect of added mass on RMS acceleration (a) $\mathrm{x}$-axis and (b) z-axis

\section{Vibration Attenuation of motorcycle handlebar using DVA}

Figure 6 show the RMS acceleration level of the motorcycle handlebar during road test before and after the installation of DVA. Each response spectra varies with different input speed. Focussing on the x-axis with the tuned DVA frequency of $200 \mathrm{~Hz}$, the attenuation ranges from $59 \%$ to $68 \%$. Based on the highest vibration peak amplitude, the attenuation level for $30 \mathrm{kmh}^{-1}, 40 \mathrm{kmh}^{-1}$ and $50 \mathrm{kmh}^{-1}$ are $59 \%, 60 \%$ and $68 \%$ respectively. A lower vibration amplitudes are measured in the z-axis. With the tuned DVA ferquency of $200 \mathrm{~Hz}$, the attenuation level is between $34 \%$ to $47 \%$. For the full response spectrum, based on the highest vibration peak amplitude the attenuation level for each speed is shown in figure 7 . It is interesting to note that the attenuation level is inreasing with the speed which indicate that the DVA is functioning well, particularly attenuating the vibration on the resonant frequency of the handlebar. The level of attenuation at 59-68\% is typical and comparable to the attenuation level achieved by using DVA elsewhere [7][14][15][16]. 
a) $\mathrm{x}$-axis without DVA

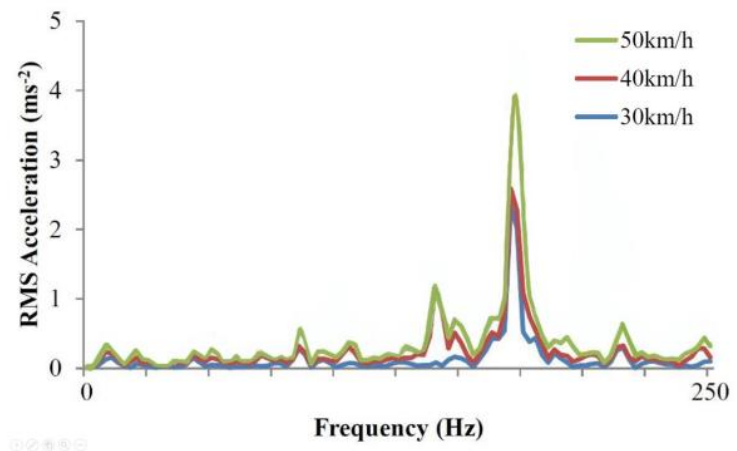

b) $\mathrm{x}$-axis with DVA

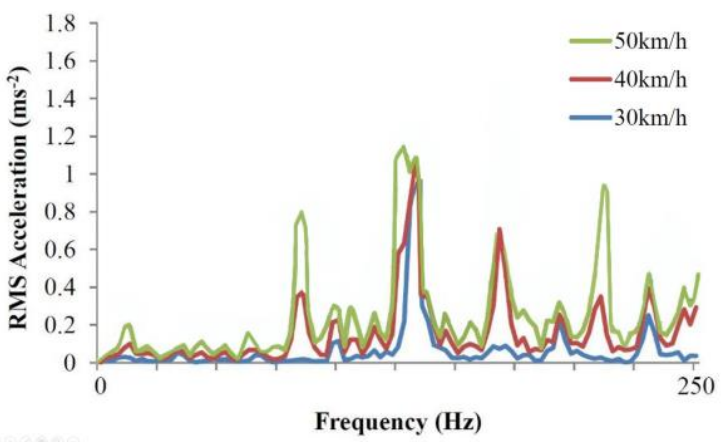

Figure 6. RMS vibration acceleration during road test with and without DVA

(a) $x$-axis without DVA and (b) $x$-axis with DVA

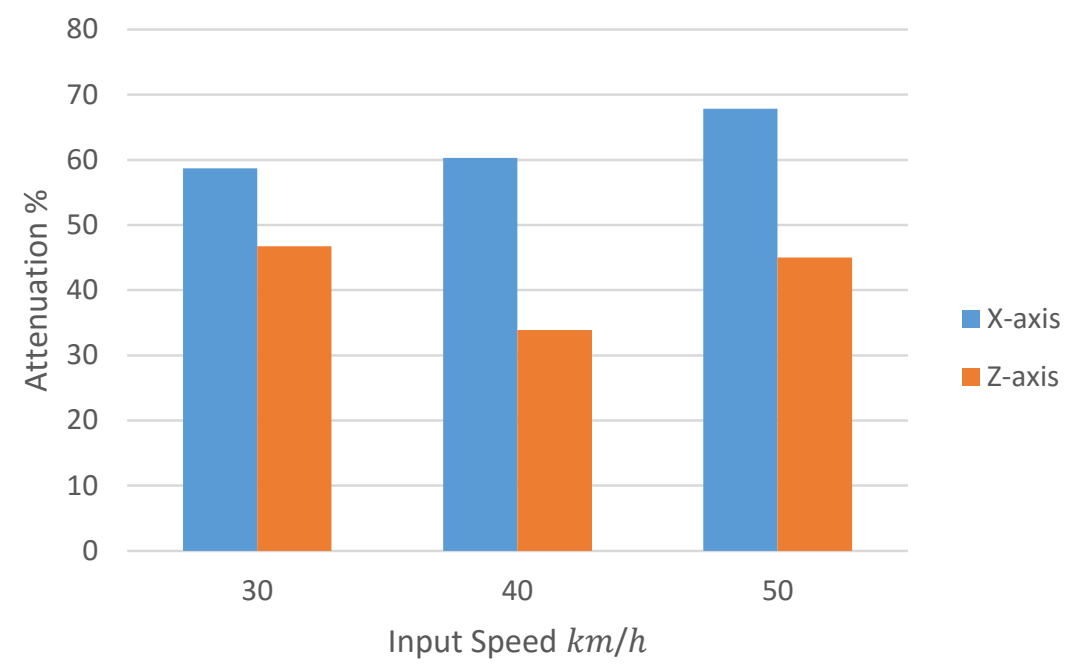

Figure 7. Vibration attenuation level at different input speed

\section{CONCLUSION}

A dynamic vibration absorber and added mass are deployed to attenuate the motorcycle handlebar vibration. The peak attenuation level of 59-68 \% are achieved depending on the speed of $30-50 \mathrm{kmh}^{-1}$.

\section{ACKNOWLEDGEMENTS}

The authors would like to thank the Ministry of Higher Education and USM for providing the facilities and the research opportunity through Bridging Grant A/C 304/PMekanik/6316214 


\section{REFERENCES}

[1] Anisa Holmes, "The Top 5 Cycling \&amp; Motorcycling Countries in the World - Dalia Research,” Dalia, 2017. [Online]. Available: https://daliaresearch.com/blog-the-top-5-cycling-motorcycling-countries-in-theworld/. [Accessed: 27-Jun-2017].

[2] J. M. Noh, K. A. M. Rezali, A. As, and N. A. A. Jalil, "Transmission of Vibration from Motorcycle Handlebar to the Hand," J. Soc. Automot. Eng. Malaysia, vol. 1, no. 3, pp. 191-197, 2017.

[3] Y. Patel, J. Trivedi, S. Dadhaniya, B. Patel, A. J. Sheth, U. G. Student, and P. A. J. Sheth, "Design and Development of Tuned Vibration Absorber to Control Engine Body Vibration in Idling and Running Condition," Int. J. Eng. Sci., vol. 11561, no. 5, pp. 11561-11563, 2017.

[4] M. J. Griffin, "Dose-effect relationships for hand-transmitted vibration.," Handb. Hum. Vib., pp. 609-631, 1990.

[5] K. Karmegam, M. Y. Ismail, S. M. Sapuan, N. Ismail, M. T. Shamsul Bahri, S. Shuib, and P. Seetha, "A study on motorcyclist's riding discomfort in Malaysia," Eng. e-Transaction, vol. 4, no. 1, pp. 39-46, 2009.

[6] S. M. Mirbod, H. Yoshida, M. Jamali, K. Masamura, R. Inaba, and H. Iwata, "Assessment of hand-arm vibration exposure among traffic police motorcyclists," Int. Arch. Occup. Environ. Health, vol. 70, no. 1, pp. 22-28, 1997.

[7] A. Fasana and E. Giorcelli, "A vibration absorber for motorcycle handles," Meccanica, vol. 45, no. 1, pp. 79-88, 2010.

[8] L. M. Roseiro, M. A. Neto, A. M. Amaro, C. J. Alcobia, and M. F. Paulino, "Hand-arm and whole-body vibrations induced in cross motorcycle and bicycle drivers," Int. J. Ind. Ergon., vol. 56, pp. 150-160, 2016.

[9] N. A. Mann and M. J. Griffin, "Effect of contact conditions on the mechanical impedance of the finger.," Cent. Eur. J. Public Health, vol. 4, no. 1, pp. 46-49, 1996.

[10] P. Marcotte, Y. Aldien, P.-É. Boileau, S. Rakheja, and J. Boutin, "Effect of handle size and hand-handle contact force on the biodynamic response of the hand-arm system under zh-axis vibration," J. Sound Vib., vol. 283, no. 3-5, pp. 1071-1091, 2005.

[11] K. A. Md Rezali and M. J. Griffin, "Transmission of vibration through gloves: effects of material thickness," Ergonomics, vol. 60, no. 1, pp. 69-81, 2016.

[12] P. Watts, "On a method of reducing the rolling of ships at sea," Trans. Inst. Nav. Archit., vol. 24, pp. 165-190, 1883.

[13] H. Frahm, "Device for damping vibrations of bodies." Google Patents, 18-Apr1911.

[14] Y. H. Ko, O. L. Ean, and Z. M. Ripin, "The design and development of suspended handles for reducing hand-arm vibration in petrol driven grass trimmer," Int. J. Ind. Ergon., vol. 41, no. 5, pp. 459-470, 2011.

[15] E. V Golysheva, V. I. Babitsky, and A. M. Veprik, "Vibration protection for an operator of a hand-held percussion machine," J. Sound Vib., vol. 274, no. 1-2, pp. 351-367, 2004.

[16] A. J. Sheth, "Vibration control of a hand blender with the tuned vibration absorber," Int. J. Adv. Res. Eng. Appl. Sci., vol. 4, no. 10, pp. 22-30, 2015. 